\title{
Women's Experiences of Midwifery Support during Pregnancy A step in the Validation of the Scale: "The Mother Perceived Support from Professionals"
}

Stina Thorstensson, Maria Nilsson, Linda Olsson, Elisabeth Hertfelt-Wahn and Anette Ekström*

School of Health and Education, University of Skövde, Skövde, Sweden

*Corresponding author: Anette Ekström, Associate Professor, School of Health and Education, University of Skövde, Skövde, Sweden; Tel:0046 500 4484 14; E-mail: anette.ekstrom@his.se

Received date: Feb 27, 2015, Accepted date: Mar 27, 2015, Published date: Apr 3, 2015

Copyright: ( 2015 Ekström A et al. This is an open-access article distributed under the terms of the Creative Commons Attribution License, which permits unrestricted use, distribution, and reproduction in any medium, provided the original author and source are credited.

\begin{abstract}
Background: Pregnancy can be physically and emotionally stressful for the parents, which means they need adequate professional support. Easy-to-use, validated scales are important in order to develop professional support in Antenatal care as well as in research.
\end{abstract}

The aim: Our aim was to illuminate pregnant women's experience of professional support at the Antenatal care, in relation to the Mother-Perceived-Professionals-Support (MoPPS) scale.

Method: A qualitative study design using the method "Think aloud" with both inductive and deductive approaches, was used. Five first-time mothers were interviewed with open questions followed by questions related to the MoPPS scale items. Data was analyzed using inductive and deductive qualitative content analyses.

Results: The inductive analysis resulted in one theme: "Professional support from midwives made women created a feeling of security and unique or rejected and lonely during pregnancy" and three categories: "Continuity and competence", "Perceiving trust or not" and "Parental groups or individual visits". The deductive analysis described the mothers' understanding of each item. However, coherence between the inductive and deductive analyses varied and the MoPPS-scale needs development.

Conclusion: The result shows that women's experience of professional support affects their sense of feeling safe or lonely during pregnancy. Important for midwives were to meet the women's unique individual needs. The MoPPS scale was considered to be relevant and easy to understand, but it needs development to include questions about continuity, parental groups and the perception of midwives' competence, which all were important for the women during their pregnancies.

Clinical implications: To offer adequate professional support for women during pregnancy, midwives need to meet the women's unique individual needs with both medical and supportive knowledge.

Keywords: Professional; Scale; Validation; Mother; Parent

\section{Introduction}

Pregnancy can be physically and psychologically stressful for a parent which means that they often need professional support [1]. During pregnancies, women are recommended regular free checkups at antenatal care by midwives [2] and in Sweden nearly all pregnant women follow these recommendations $[3,4]$. Becoming a mother for the first time is often described as overwhelming and chaotic with mixed feelings [5-7] and mothers describe disappointment when mainly receiving information while also needing emotional support during childbirth $[8,9]$. However, while midwives claim they offer this support, mothers describe a lack of support [10]. Especially women with a low education feel dissatisfied with the lack of emotional support from the midwives in antenatal care, but in contrast to other studies the women in this study also experienced medical support as poor [11]. Midwives in antenatal care also identify medical risks in order to prevent complications [12]. Professional support during pregnancy is likewise important since it has an impact on first-time mothers' feelings for and relations to their babies $[13,14]$. Professional support is directly available but limited to those with professional knowledge while social support depends on reciprocity and relations within the social network [15].

Professional support is somewhat different from care [14] as well as different from social support [15]. Support can be described as emotional (i.e. creating a sense of belonging and security), encouraging (i.e. offering reassurances about competence in actual situations), informative (i.e. offering information in relation to actual situations) and practical (i.e. offering practical help in actual situations) [16]. Further research is needed to increase our understanding of women's experiences of professional support during pregnancy and childbirth as well as our understanding of professional support overall $[7,17,18]$. Validated and simple to use scales are also important when developing maternity services as well as in related research. This study is part of a larger research project to develop such a tool, the Mother-Perceived-Professionals-Support (MoPPS) scale, to increase awareness of support. Therefore the aim of this study was to illuminate pregnant women's experience of professional support in 
Citation: Ekström A, Thorstensson S, Nilsson M, Olsson L, Wahn EH (2015) Women's Experiences of Midwifery Support during Pregnancy A step in the Validation of the Scale: "The Mother Perceived Support from Professionals". J Nurs Care 4: 241. doi: $10.4172 / 2167-1168.1000241$

Page 2 of 6

Antenatal care, in relation to the Mother-Perceived-ProfessionalsSupport (MoPPS) scale.

\section{Material and Method}

For this study, a qualitative design using the method "Think aloud" [18] with both an inductive and deductive approach was used. Qualitative approaches, are commonly used to describe phenomena about which little is known, to capture meaning (in the form of individuals' thoughts, feelings, behaviors, etc.) instead of numbers, and to describe processes rather than outcomes [19]. Individual interviews were used for data collection to capture the direct voices of the women, an important factor when aiming to measure abstract phenomena [20,21]. The interviews were performed using open questions followed by questions based on the MoPPS-scale items described under the MoPPS section below. This data collection method aimed at illuminating the participants' perception [22] of their experience of professional support. The data were analyzed using both inductive and deductive qualitative content analyses [23].

\section{Participants}

A purposive sampling strategy [24] was adopted, aiming for variation in age, education levels and social class. Initially, we conducted a pilot interview (with a woman who met the inclusion criteria) to test if the open question is understandable and captures what the open question intends to measure. Then we interviewed five more women to answer the purpose. The participating varied in age between 23 to 29 years old, three of them were first-time mothers and two of them were expecting their second child. The women had different levels of education, from elementary school to university, they were all in gestational week 35-36 and they were living in stable relationships. Inclusion criteria: Women in the third trimester, uncomplicated pregnancy, singletons, and who understood the Swedish language so that the instrument of research could be completed without an interpreter.

\section{The MoPPS-scale}

The Mother-Perceived-Professionals-Support (MoPPS) scale is a 7graded scale Likert scale, with opposing statements. The MoPPS scale consists of a question about how mothers perceive professional support from health care professionals followed by eight statements: "Sensitive/Not at all sensitive"; "Understanding/Not at all understanding"; "Supportive/Not at all supportive"; "Had plenty of time/Had very little time"; "Gave enough information about breastfeeding/Did not give enough information about breast-feeding"; "Were calm/Were under stress"; "Gave good preparations for the parenting role /Gave no preparations for the parenting role" and "Gave good information about the needs of the baby/Gave no information about the needs of the baby". The women were asked to grade their perception on a 7 -grade scale that was sometimes reversed in order to avoid routine-like responses [24].

\section{Data collection procedure}

Pregnant women were approached by a midwife at the Antenatal center. This midwife offered written information and when mothers accepted to participate they were contacted by authors MN and LO. All interviews were recorded and performed by the authors together ( $\mathrm{MN}$ and $\mathrm{LO}$ ) to get different points of view and to minimize the risk of misinterpretation when analyzing the data. To ensure good quality of the interviews, a pilot interview was performed before the actual data collection began [24]. The pilot interview helped improve both the interview technique and approach of the interview. Three of the interviews were performed at the Antenatal center and two of the interviews were performed over the phone. The interviews started with an open question: Describe your experience of professional support from health-care professionals at the Antenatal center? During the interviews, the participants were encouraged to reflection their experience and probing questions were used. After the open question, the mothers answered the questionnaire on the MoPPS scale. After answering the questionnaire, the mothers were asked to describe their thoughts about each item and why they answered as they did. All interviews were recorded and then transcribed verbatim.

\section{Data analysis}

The audio-taped interviews with the women were transcribed verbatim and analysed separately using latent content analysis. The transcripts from the women respectively were scrutinized several times, discussed, compared, and validated. Familiarity with the text was achieved by repeated reading. Words and sentences containing information relevant to the research questions were identified as meaning units, which were condensed and coded. The codes were grouped into subcategories and then categories. Data were further analysed by reading across the categories, searching for new associations and meanings in the data. In the final step, findings were discussed and reflected upon, taking the research issues into account, and an overall theme emerged.

Regarding the answers to the MoPPS-scale items, a deductive qualitative content analysis was used [23]. The women's answers for each item were read through and analyzed in order to understand their thoughts for each item, and the meaning of each item was identified. When the women give low or high answers on the MoPPS-scale items, their individual descriptions of these MoPPS scale items were analyzed. This procedure allowed for comparisons in order to understand what inference could be drawn [25] from the different items of the MoPPS scale.

\section{Ethical considerations}

Our study was approved by the Ethical Board of Gothenburg (EPN) from an ethical point of view, Number: 405 09, before any data collection began. The head of service of the Antenatal center was given information about the study and gave her /his approval for us to undertake this study. The participating women were given written and oral information about the study, as well as information explaining that their participation was voluntary and that they could withdraw from the study at any time without having to provide a reason and without their care being affected.

\section{Results}

The women's experiences and reflections of receiving professional support were presented as a single main theme, "Professional support from midwives made women created a feeling of security and unique or rejected and lonely during pregnancy." This theme had three categories: "Continuity and competence," "Perceiving trust or not"," and "Parental groups or individual visits"(Table 1). Each category and its subcategories were presented using direct quotations in a conversational format. The citations have fictitious name. 
Citation: Ekström A, Thorstensson S, Nilsson M, Olsson L, Wahn EH (2015) Women's Experiences of Midwifery Support during Pregnancy A step in the Validation of the Scale: "The Mother Perceived Support from Professionals". J Nurs Care 4: 241. doi: $10.4172 / 2167-1168.1000241$

Page 3 of 6

\begin{tabular}{|l|l|}
\hline THEME & CATEGORIES \\
\hline $\begin{array}{l}\text { Professional support from midwives } \\
\text { made women created a feeling of } \\
\text { security and unique or rejected and } \\
\text { lonely during pregnancy }\end{array}$ & Continuity and competence \\
\cline { 2 - 2 } & Perceiving trust or not \\
\hline
\end{tabular}

Table 1: Overview of theme, main categories

\section{Professional support from midwives made women created a feeling of security and being unique or rejected and lonely during pregnancy}

Professional support from midwives was influenced by the women's perception of midwives' competence and continuity in meetings as well as the women's perception of trust in midwives. Competence, continuity and trust affected the women's sense of feeling safe and unique or feeling rejected and lonely. During their pregnancies, the women also described a need for social support through parental groups and professionals' support from midwives could not compensate for the lack of social support from other parents.

\section{Continuity and competence}

The women often met the same midwife throughout their pregnancies and this created a feeling of safety in the women. This continuity contributed to a secure relation, increased the chance of a more open climate and as a consequence gave an opportunity for the women to ask more intimate questions. The women experienced the midwife as "their" midwife. They described how midwives did not answer questions in a routine-like way which was experienced as being offered individual support.

"Midwives meet many parents-to-be who probably ask the same questions and talk about the same things ... but as a mother-to-be I should not perceive this, one shall experience that when I'm here, it's about me and my pregnancy and that I feel that I am listened to" (Eve).

That the midwives listened and acknowledged the women's individual and unique needs for support meant that the women felt "seen as individuals" which created a sense of feeling safe and unique. The women described it as important that they could trust the competence of their midwife and they described midwives as involved and with high medical skills. It was fun to go to the meetings at the antenatal center and the women looked forward to it.

“...Yes, but I have received answers to the questions I had... and the questions one has had and so on... I think it feels great..." (Margreth)

The midwives' knowledge and competence were perceived as more important than a friendly behavior. The women described the midwives as qualified when they were given advice such as how to alleviate pregnancy symptoms. For the women, it was important that the midwives shared their knowledge and informed about pregnancy. Both written and verbal information was perceived as positive and that the midwives answered questions and discussed the women's concerns with them. For the women, their pregnancies led to several questions and concerns about perceived problems that often belong to normal pregnancies. The midwifes' professional support to the women was described as reducing concerns.
The women expected the midwives to be competent regarding medical tests. The midwives' competence was described as important when they examined the women during the pregnancy, for example with blood tests or checking blood pressure, in order to detect if something was not normal. When the women perceived a lack of competence in midwives, it decreased their sense of feeling safe and had a negative influence on their perception of professional support. The women perceived lack of competence in midwives when midwives did not answer their questions.

"She was really nice and easy to talk to and all that stuff, but I still had this feeling that she missed something" (Anna)

For women to feel safe and to trust the midwife, it was important that midwives were attentive to the women's individual needs. When midwives ignored their questions or problems, the women felt rejected and disregarded. When the midwives did not answer questions or when the women themselves had to question the check-ups it created a sense in the women that the midwife lacked knowledge or was not in control of the situation. Then the women did not feel safe during meetings with the midwives and they described it as due to ignorance or stress among the midwives.

\section{Perceiving trust or not}

The women described that trust in the midwives was often established directly at the first personal meeting. This first meeting was often perceived as positive and it was described that the characteristics of the midwives had an impact on how the women experienced professional support at this first meeting. The women described the midwives' ways of being in positive words such as: positive, happy about their pregnancies, generally pleasant, harmonious, caring, safe and sweet.

It felt as if she (the midwife) really cared, she asked how it was and she was positive all the time and said; Oh how exciting and Oh how cool... (Mary)

These characteristics of midwives influenced the women's feeling of being seen and listened to which induced a sense of trust, feeling safe and being unique among the women. Trust in the midwives was also created when the women experienced that the midwives were available for them. Being available was described as having enough time in the first meeting in the beginning of the pregnancy. When the women felt they had enough time during the first meeting with midwives, they did not feel so alone in the beginning of their pregnancies. However, the disposition of visits influenced the women's perception of the midwives' availability. In the early pregnancy, when meetings were sparse, the women described a feeling of loneliness and longing for talking to a professional caregiver.

\section{"It felt like there was a big vacuum in between ..." (Margreth)}

This experience led to a sense of the midwives not being available in order to meet the women's needs for support which decreased the women's trust in the midwives. The midwife being available also meant that the women felt they could get in contact also between regular visits if they needed to. It was important for their sense of feeling safe and unique that the midwives were available for them and that they could have an extra meeting.

"She's always there, she always says if there is anything you want to ask,... just call me, then we'll book a new meeting... I know she's there for me... (Elizabeth) 
Citation: Ekström A, Thorstensson S, Nilsson M, Olsson L, Wahn EH (2015) Women's Experiences of Midwifery Support during Pregnancy A step in the Validation of the Scale: "The Mother Perceived Support from Professionals". J Nurs Care 4: 241. doi: $10.4172 / 2167-1168.1000241$

Page 4 of 6

The midwives' availability was important for the women's sense of trust in midwives and this included that they were able to reach the midwives, being guaranteed meetings and to have the possibility to call the clinic if they felt it necessary.

\section{Parental groups or individual visits}

When the midwives lacked time at the antenatal clinic, they did not organize parental groups. The women described how this meant an absence of social support from other parents. The midwives tried to compensate for the lack of parental groups and replaced them with individual meetings.

"It is the social contact we had wanted from parent groups, and it cannot be compensated for by increasing the length of time with the midwife, so we are disappointed"(Margareth)
However, for the women, individual meetings with the midwife were something else than meeting other parents in parental groups. Professional support in individual meetings could not compensate for the lack of social support from other parents. The women expressed their disappointment that the midwife did not understand that professional support cannot replace social support. This affected their experience of professional support negatively and increased their sense of loneliness.

\section{Result deductive analysis}

An overview of analysis of the MoPPS-scale items is shown in Table 2. An overall description of the meaning of each item is followed by a description of high and low assessments for each item (Table 2).

\begin{tabular}{|c|c|c|c|c|}
\hline MoPPS-scale items & $\begin{array}{l}\text { Answers: Lowest to highest } \\
(n=5)\end{array}$ & Overall meaning of the scale item & $\begin{array}{l}\text { Meaning when responding } \\
\text { with a low mark }\end{array}$ & $\begin{array}{l}\text { Meaning when responding with a } \\
\text { high mark }\end{array}$ \\
\hline $\begin{array}{l}\text { Not at all sensitive } \\
\text { Sensitive }\end{array}$ & 7 & $\begin{array}{l}\text { The midwives listen attentively and } \\
\text { are engaged and available. This } \\
\text { creates a sense of security, being } \\
\text { unique and cared about among the } \\
\text { women. }\end{array}$ & Not relevant & $\begin{array}{l}\text { Midwives acknowledge the woman as } \\
\text { an individual and show a genuine } \\
\text { interest in the women, even outside } \\
\text { business hours. Midwives offer } \\
\text { reassurance (encouraging support), } \\
\text { respond to questions, even trifle ones } \\
\text { and respond to the women's } \\
\text { expectations and reason with them. }\end{array}$ \\
\hline $\begin{array}{l}\text { Not understanding } \\
\text { Understanding }\end{array}$ & 7 & $\begin{array}{l}\text { Midwives try to understand the } \\
\text { women's expectations and feelings } \\
\text { and offer reassurance (support), } \\
\text { with no regard to the backgrounds } \\
\text { or other differences. }\end{array}$ & Not relevant & $\begin{array}{l}\text { Midwives offer the women } \\
\text { reassurance (appraisal support) } \\
\text { when acknowledging their problems } \\
\text { and help them understand what was } \\
\text { good for them without judging. }\end{array}$ \\
\hline $\begin{array}{l}\text { Not at all supportive } \\
\text { Supportive }\end{array}$ & 7 & $\begin{array}{l}\text { Midwives are available, listen and } \\
\text { answer questions. They are } \\
\text { reassuring, show an interest and } \\
\text { engagement in the women. Support } \\
\text { could be both practical and } \\
\text { emotional, but midwives have to be } \\
\text { understanding to be supportive. }\end{array}$ & Not relevant & $\begin{array}{l}\text { Midwives follow up on problems and } \\
\text { the women's wellbeing and help with } \\
\text { practical issues like answering } \\
\text { questions or offer to contact other } \\
\text { professionals when needed. }\end{array}$ \\
\hline $\begin{array}{l}\text { Had plenty of time/ } \\
\text { Had very little time }\end{array}$ & $6-7$ & $\begin{array}{l}\text { Midwives take time to be available } \\
\text { and flexible. Having time or not } \\
\text { affect the quality of the women's } \\
\text { meeting with midwives, which was } \\
\text { evident through body language and } \\
\text { tone of voice. }\end{array}$ & Not relevant & $\begin{array}{l}\text { Midwives take time to meet the } \\
\text { women and when necessary they } \\
\text { allow more time than scheduled. } \\
\text { Despite knowing that midwives were } \\
\text { busy, the women described them as } \\
\text { relaxed and calm and a contrast to } \\
\text { their worries. }\end{array}$ \\
\hline $\begin{array}{lr}\text { Providing } & \text { enough } \\
\text { information } & \text { about } \\
\text { breastfeeding } & \\
\text { Not providing } & \text { enough } \\
\text { information } & \text { about } \\
\text { breastfeeding } & \end{array}$ & $1-6$ & $\begin{array}{l}\text { Written and oral information about } \\
\text { breastfeeding. Both practical and } \\
\text { psychological tips such as where to } \\
\text { turn to if problems would arise. }\end{array}$ & $\begin{array}{l}\text { Midwives have not yet talked } \\
\text { about breast-feeding. }\end{array}$ & $\begin{array}{l}\text { Information offered at parental } \\
\text { meetings could be about problems } \\
\text { and solutions and that breastfeeding } \\
\text { requires patience. }\end{array}$ \\
\hline $\begin{array}{l}\text { Being under stress } \\
\text { Being calm }\end{array}$ & 7 & $\begin{array}{l}\text { A feeling that midwives are calm, } \\
\text { based on their attitudes, body- } \\
\text { language and how things were said, } \\
\text { all of which is important. }\end{array}$ & & $\begin{array}{l}\text { During meetings, midwives are } \\
\text { present, take their time and are } \\
\text { organized. They use simple language } \\
\text { and go through information } \\
\text { thoroughly. }\end{array}$ \\
\hline $\begin{array}{l}\text { Providing good } \\
\text { preparations for the } \\
\text { parenting role } \\
\text { Not providing } \\
\text { preparations for the } \\
\text { parenting role }\end{array}$ & $1-6$ & $\begin{array}{l}\text { Midwives offer information and } \\
\text { advice about delivery and time with } \\
\text { the baby, such as expectations and } \\
\text { preparations as well as offering } \\
\text { information about where to turn to if } \\
\text { problems would arise. }\end{array}$ & $\begin{array}{l}\text { Have not had a parental } \\
\text { group or individual talk about } \\
\text { these things with the midwife } \\
\text { yet. }\end{array}$ & $\begin{array}{l}\text { Midwives offer calm and accurate } \\
\text { information about both positive and } \\
\text { negative preparations, offer written } \\
\text { information and answer questions } \\
\text { about i.e. colic. }\end{array}$ \\
\hline
\end{tabular}


Citation: Ekström A, Thorstensson S, Nilsson M, Olsson L, Wahn EH (2015) Women's Experiences of Midwifery Support during Pregnancy A step in the Validation of the Scale: "The Mother Perceived Support from Professionals". J Nurs Care 4: 241. doi: $10.4172 / 2167-1168.1000241$

Page 5 of 6

\begin{tabular}{|c|c|c|c|c|}
\hline $\begin{array}{l}\text { Providing good } \\
\text { information about the } \\
\text { needs of the baby } \\
\text { Not providing } \\
\text { information about the } \\
\text { needs of the baby }\end{array}$ & $3-7$ & $\begin{array}{l}\text { Midwives offer information and } \\
\text { knowledge about the baby's basic } \\
\text { needs such as love and food. }\end{array}$ & $\begin{array}{l}\text { Have not yet talked about } \\
\text { these issues. }\end{array}$ & $\begin{array}{l}\text { Women are offered both written and } \\
\text { oral information in parental groups } \\
\text { even though not all expectations } \\
\text { have been discussed yet. }\end{array}$ \\
\hline
\end{tabular}

Table 2: Assessment of the MoPPS scale

\section{Comparing inductive and deductive results}

The analysis of the open questions summarizes how the women in their own words describe the professional support. The women's perception of the midwives' competence and continuity in meetings was important for their experience of professional support. Gaining trust in the midwife or not included the midwives' personal characteristics, a supportive first meeting and perceiving the midwife as available for their unique individual needs. The women's statement in relation to the MoPPS-scale items has similar descriptions of support, but in other words.

However, the MoPPS scale needs further development. The information in the MoPPS scale regarding breastfeeding, parental role and needs of the child was nothing the women mentioned during the interview. They described that these were aspects that were difficult for them to evaluate before the baby was born. The MoPPS scale depicts various aspects of knowledge and information, but does not mention parent groups specifically. Competence was described as an important skill among midwives because the women were in a vulnerable position, but there was nothing of a similar meaning in any of the MoPPS-scale items. The first meeting was important in order to gain trust in the midwife and to decrease the women's sense of loneliness in the early pregnancy. During pregnancy, it was important to create a good relationship because the women then dared to ask more intimate questions. This relationship was created by continuity and collaboration between midwives and the women. There is no part of the MoPPS scale covering the continuity or importance of the first meeting.

The MoPPS scale questionnaire was experienced as simple to fill in, and that it took up the relevant parts of professional support. That the women gave responses mostly in the positive extremes of the scale is consistent with the results of the interviews where midwives are mostly described positively. Answers to the open questions reveal somewhat more of nuances in the women's experience, something which is a challenge to capture in a scale.

\section{Discussion}

The result shows that women's experience of professional support during pregnancy affect women's confidence and trust in midwives. Professional support from midwives made women created a feeling of security and unique or rejected and lonely during pregnancy. Continuity and competence were important as well as gaining trust in midwives. When women felt trust in midwives, a feeling of being safe emerged. Important for the pregnant women was their experience of being seen as an individual, which was mostly founded in the midwives' availability, continuity in meetings and competence. The women expressed disappointment when the midwives did not understand that professional support in individual meetings cannot replace the social support in parental support groups. This affected their experience of professional support as negative and increased their sense of loneliness. The MoPPS scale was considered to be easy to understand, but it could be developed to include questions about the midwives' competence, continuity in meetings and how they arranged and facilitated social support in parental groups.

The results of this study show that women were overall satisfied with the support and care from the midwives at the antenatal center. However, there was some dissatisfaction about the midwives' competence such as not answering questions or the women having to question the checkups and then the knowledge of the midwives felt inadequate. Earlier research describes that discontent with the emotional support in antenatal care occurs when midwives are not sensitive to the women's feelings [1]. Perhaps dissatisfaction with the midwives' competence as a result in our study is mainly about midwives not meeting individual needs. The result of our study also shows that it was important with professional continuity throughout pregnancy. The women felt secure when the midwives were perceived as available and competent, otherwise the women felt less safe and lost their trust in the midwives. This is in line with earlier research that to establish a trusting relationship, midwives need to offer women the time they need, creating a caring environment, be engaged and present [11]. A trusting relationship, as shown in our study, allows the women to raise intimate or sensitive questions. Other research also describes that security is created by early and continuous information to the women [11]. This is in line with our result that the first meeting was important for the women in order to gain trust in midwives and also to reduce their sense of loneliness in the early pregnancy. These results put together illustrate the importance of professional continuity in order to achieve adequate professional support for women during pregnancy. Perhaps experiencing incompetence is closely linked to gaining trust in midwives such as getting answers and being seen as an individual. Hence both medical and supportive skills in midwives are important for women to feel safe and unique in antenatal care. Research describes that if women for some reason doubt midwives' professional expertise, this creates a concern. Lundgren and Berg describe women's sense of being handed over to the prenatal care. When midwives meet women in this sense, they should be accessible and responsive. Midwives should have both theoretical and practical knowledge, i.e. grounded knowledge, particularly if complications arise and women may become even more vulnerable. The environment also has an impact on how professional support is perceived, that it must be peaceful and harmonious rather than stressful [14]. This is in line with our results that the women perceived the midwives as lacking competence when the midwives failed to respond to the women's unique individual needs.

The results of this study show that parental groups were important for the pregnant women, for example to create networks and increase their social support. In earlier research it has been shown that the quality of professional support depends on midwives' ability to respond to a woman's unique needs, otherwise a feeling of uncertainty emerges. The partner is an important part of the social support for 
Citation: Ekström A, Thorstensson S, Nilsson M, Olsson L, Wahn EH (2015) Women's Experiences of Midwifery Support during Pregnancy A step in the Validation of the Scale: "The Mother Perceived Support from Professionals". J Nurs Care 4: 241. doi: $10.4172 / 2167-1168.1000241$

Page 6 of 6

pregnant women and thus important for midwives to pay attention to [11]. However, the partner was not mentioned by the women in our study.

The purpose of the MoPPS scale is to develop care in childbirth and is based on the theoretical basis of social and professional support. Parts of the MoPPS scale can illuminate the experience of support $[17,7]$. When comparing results from inductive and deductive analyses, the MoPPS scale is the scale that needs development. Questions involving continuity, midwives competence and parent education were lacking. Professional support should aim at strengthening social support [15] so this aspect needs to be developed in the MoPPS scale.

The study is limited by its small sample size, but the context and the participants are described as clearly as possible in order to facilitate the transferability of the results. However, in qualitative research, the amount of data is generally important for the quality of the study. The women included in the study varied in age, childbirth experience and level of education, which could be considered as strengthening the reliability of the study. Variation in experience among the participants is strengthening in regards to the results [24]. Having both an inductive and deductive approach proved strengthening for the study as a whole and gave information of importance in validation and development of the MoPPS scale.

\section{Conclusion}

The result shows that women's experience of professional support affects their sense of feeling safe and unique or rejected and lonely during pregnancy. Midwives competence and continuity in meetings as well as gaining trust or not in midwives influence these feeling. When the professional support did not meet the women's individual needs, such as midwives not answering their questions or not offering parental groups, the women felt rejected and lonely and did not feel safe. The MoPPS scale was considered to be relevant and easy to understand, but it needs development by including questions about continuity, parental groups and perception of midwives' competence, which is important for women during pregnancy.

\section{Clinical Implications}

To offer adequate professional support for women during pregnancy, midwives need to meet the women's unique individual needs with both medical and supportive knowledge.

\section{References}

1. Widarsson M, Kerstis B, Sundquist K, Engström G, Sarkadi A (2012) Support needs of expectant mothers and fathers: a qualitative study. J PerinatEduc 21: 36-44.

2. WHO. (2006). Pregnancy, Childbirth, Postpartum and Newborn Care: A guide for essential practice, guinea.

3. Danielson, M., Berglund, T., Forsberg, M., Larsson, M., Rogala, C. \&Tydén, T. (2009). Sexual and Reproductive Health. In Socialstyrelsen (Ed.), (pp. 261-280). Stockholm: Statens Folkhälsoinstitut.

4. SFOG. (2008). Mödrahälsovård, Sexuelloch Reproduktiv Hälsa Rapport Nr 59: Svensk Förening för Obstetrikoch Gynekologi.
5. McKellar V., Pincombe J., Henderson M. (2002). Congratulations you're a mother: A strategy for enhancing postnatal education for first-time mothers investigated through an action research cycle. Australian College of Midwives Incorporated, 15: 24-31

6. Raphael-Leff, J. (2005). Psychological processes of childbearing (fourth ed.). Guildford: Anna Freud Centre.

7. Thorstensson S., Hertfelt-Wahn E., Langius-Eklöf A., Ekström A. (2012). Evaluation of the Mother-to-Infant relation and feeling scale: Interviews with first-time mothers' for feelings and relation to their baby three days after birth. International Journal of Nursing and Midwifery, 4: 8-15.

8. Ekström A, Widström AM, Nissen E (2003) Breastfeeding support from partners and grandmothers: perceptions of Swedish women. Birth 30: 261-266.

9. Razurel C., Bruchon-Schweitzer M., Dupanloup A., Irion O., Epiney, M. (2011). Stressful events, social support and coping strategies of primiparous women during the postpartum period: a qualitative study. Midwifery, 27: 237-242.

10. Bäckström CA, Wahn EI, Ekström AC (2010) Two sides of breastfeeding support: experiences of women and midwives. Int Breastfeed J 5: 20.

11. Hildingsson I, Rådestad I (2005) Swedish women's satisfaction with medical and emotional aspects of antenatal care. J AdvNurs 52: 239-249.

12. Chittleborough, C., Lawlor, D., \& Lynch, J. (2011). Prenatal Prediction of Poor Maternal and Offspring Outcomes: Implications for Selection into Intensive Parent Support Programs. Maternal Child Health Journal, 16: 909-920

13. Ekström A, Nissen E (2006) A mother's feelings for her infant are strengthened by excellent breastfeeding counseling and continuity of care. Pediatrics 118: e309-314.

14. Thorstensson, S., \&Ekström, A. (2012). Support as a Concept and with a Focus on Childbearing Journal of Nursing and Care, 1: e109.

15. Hupcey JE, Morse JM (1997) Can a professional relationship be considered social support? Nurs Outlook 45: 270-276.

16. Langford CP, Bowsher J, Maloney JP, Lillis PP (1997) Social support: a conceptual analysis. J AdvNurs 25: 95-100.

17. Thorstensson, S., Claesson, A., Packalen, A., HertfeltWahn, E., \&Ekström, A. (2014). Validating the Mother-to-Infant Relation and Feelings' scale by first-time mothers' descriptions three months after birth. Journal of Womens's Health, Issues \& Care, 3.

18. Drennan J (2003) Cognitive interviewing: verbal data in the design and pretesting of questionnaires. J Adv Nurs 42: 57-63.

19. Given, L. (2006). Qualitative research in evidence-based practice: A valuable partnership. Library hi tech, 24: 376-386.

20. Bowling, A. (2005). Measuring health. A rewiev of quality of life measurement scales (Third ed.). New York: Open University Press.

21. Butt ML, Pinelli J, Boyle MH, Thomas H, Hunsberger M, et al. (2009) Development and evaluation of an instrument to measure parental satisfaction with quality of care in neonatal follow-up. J Dev Behav Pediatr 30: 57-65.

22. Drennan J (2003) Cognitive interviewing: verbal data in the design and pretesting of questionnaires. J Adv Nurs 42: 57-63.

23. Elo S, Kyngäs $H$ (2008) The qualitative content analysis process. J Adv Nurs 62: 107-115.

24. Polit D, Beck C. (2011). Nursing Research. Generating and Assessing Evidence for Nursing Practice (9th ed.): Lippincott Williams and Wilkins.

25. Butt ML, Pinelli J, Boyle MH, Thomas H, Hunsberger M, et al. (2009) Development and evaluation of an instrument to measure parental satisfaction with quality of care in neonatal follow-up. J Dev Behav Pediatr 30: 57-65. 